\title{
Reproduction in Domestic Animals
}

\section{Onset of estrus and periovulatory events in sheep exposed to 5- and 14-days of CIDR treatment with and without eCG}

\begin{tabular}{|r|l|}
\hline Journal: & Reproduction in Domestic Animals \\
\hline Manuscript ID & Draft \\
\hline Manuscript Type: & Short Communication \\
\hline Date Submitted by the & $\mathrm{n} / \mathrm{a}$ \\
\hline Complete List of Authors: & $\begin{array}{l}\text { Uriol, Marta } \\
\text { Martinez-Ros, Paula; Universidad CEU Cardenal Herrera } \\
\text { Rios, Alejandro; Universidad CEU Cardenal Herrera } \\
\text { Encinas, Teresa } \\
\text { Gonzalez-Bulnes, Antonio }\end{array}$ \\
\hline Subject Area: & $\begin{array}{l}\text { Animal breeding < General reproduction, small ruminants < Species: , } \\
\text { Management < General reproduction }\end{array}$ \\
\hline
\end{tabular}

\section{SCHOLARONE Manuscripts}


1 Onset of estrus and periovulatory events in sheep exposed to 5- and 142 days of CIDR treatment with and without eCG

3

4

5

7

8

9

10

11

12

M. Uriol ${ }^{1, *}$, P Martinez-Ros ${ }^{2, *}$, A Rios-Abellan ${ }^{2}$, T Encinas ${ }^{1}$, A Gonzalez-Bulnes ${ }^{1,3}$ .

${ }^{1}$ Dpto. de Toxicologia y Farmacologia, Facultad de Veterinaria, UCM Madrid, Spain.

${ }^{2}$ Dpto. de Produccion y Sanidad Animal, Facultad de Veterinaria, Universidad Cardenal Herrera-CEU, CEU Universities, Valencia, Spain

${ }^{3}$ Dpto. de Reproduccion Animal, INIA, Madrid, Spain

* These authors contributed equally to this work as first authors.

Correspondence: Paula Martinez-Ros, Dpto. Produccion y Sanidad Animal, Facultad de Veterinaria, Universidad Cardenal Herrera-CEU, C/ Tirant lo Blanc, 7.46115 Alfara del Patriarca Valencia, Spain. E-mail: paula.martinez@uchceu.es

\section{Contents}

The present study supports that 5-days short-term CIDR treatments without administration of eCG are equally effective for inducing estrus behavior, preovulatory LH discharge and ovulation in sheep than classical protocols based on 14-days treatments plus eCG at CIDR withdrawal. However, the implementation of a 5-days protocol without eCG for fixed-time artificial insemination would be adapted to a later timing of ovulation $(\mathrm{p}<0.05)$. 


\section{INTRODUCTION}

Protocols for induction and synchronization of estrus and ovulation in sheep are traditionally based on the insertion of intravaginal devices with progesterone or progestagens for 12-14 days plus the administration of a single eCG dose at device removal for inducing and synchronizing ovulations among animals (Abecia et al., 2012). Currently, both the progesterone protocol and the use of eCG are under revision.

Short-term protocols (5-7 days of progesterone insertion) are increasingly used since they are equally as effective as long-term protocols for inducing ovulation and fully functional corpora lutea (Martinez-Ros et al., 2018a), with lower incidence of vaginal infections (Martinez-Ros et al., 2018b) and higher fertility yields (Swellum et al., 2015, Menchaca et al., 2018).

The future use of eCG is currently compromised by a highly active animal-right movement since it is obtained from pregnant mares. Consequently, the development of alternative protocols for induction and synchronization of estrus and ovulation without eCG is absolutely necessary. A recent study of our group found that 5-days of CIDR (Controlled Internal Drug Releasing device) treatment without eCG may allow similar reproductive yields to 14-days with eCG (Martinez-Ros et al., 2019) after natural mating.

However, modifications of the classical procedure based on 12-14 days of progesterone treatment with eCG may prejudice the yields obtained after fixed-term artificial insemination, by varying timing of preovulatory LH surge and later ovulation and mismatching them with timing of insemination. Hence, we developed a comparative study on the timings of estrus behavior, preovulatory LH peak and ovulation in sheep treated with either short- (5-days) or long-term protocols (14-days) progesterone-loaded CIDRs combined or not with eCG at device withdrawal. Such data may give substantial information for adapting protocols of artificial insemination and reaching maximal fertility. 


\section{MATERIAL AND METHODS}

52

The experiment was approved by the Universidad CEU-Cardenal Herrera Committee of Ethics in Animal Research (report CEEA17/019) and involved 22 ewes, 2-4 years-old and mean body-score of $3.4 \pm 0.2$, from the experimental farm of the University at Naquera (Valencia, Spain; latitude $39^{\circ} \mathrm{N}$ ).

Sheep were divided in four groups which, during the reproductive season (March), were treated with one intravaginal CIDR device (CIDR ${ }^{\circledR}$ Ovis, Zoetis, Madrid, Spain) for either five (groups G5) or fourteen days (groups G14) with or without the administration (groups eCG and C, respectively) of $400 \mathrm{IU}$ of eCG (Foligon ${ }^{\circledR}$, MSD Animal Health, Madrid, Spain) at CIDR removal. Sheep in the groups G5 also received one i.m. dose of 5 mg of prostaglandin $F_{2 \alpha}$ at CIDR withdrawal (Dinolytic ${ }^{\circledR}$, Zoetis, Madrid, Spain). Hence, four groups were studied: G5eCG $(n=5), \mathrm{G} 5 \mathrm{C}(\mathrm{n}=5), \mathrm{G14eCG}(\mathrm{n}=6)$ and $\mathrm{G} 14 \mathrm{C}(\mathrm{n}=6)$.

The variables evaluated were timing of onset of estrus behavior (determined with trained rams every $4 \mathrm{~h}$ from 12 to $60 \mathrm{~h}$ after CIDR withdrawal), timing of onset and characteristics of the preovulatory LH surge (determined in jugular blood samples obtained every $4 \mathrm{~h}$ from 32 to $84 \mathrm{~h}$ after CIDR withdrawal), timing of ovulation (determined by transrectal ultrasonography every $4 \mathrm{~h}$ from 48 to $84 \mathrm{~h}$ after CIDR withdrawal) and ovulation rate (determined at Day 11 of the induced estrous cycle). The characteristics of the preovulatory LH surge were evaluated by using a commercial enzimoimmunoassay kit $\left(\right.$ LH Detect ${ }^{\circledR}$, INRA, Tours, France; sensitivity of $0.01 \mathrm{ng} / \mathrm{mL}$ and inter- and intra-assay variation coefficients of $7.4 \%$ and $8.5 \%$, respectively). Timing of ovulation and number of corpora lutea were determined by transrectal ultrasonography (Aloka SSD500 with a 7.5 MHz linear-array probe, Aloka Co. Ltd., Tokyo, Japan). Statistical analysis was performed using chi square test $\left(\right.$ SPSS $^{\circledR} 22.0$, IBM Corporation, New York NY, USA). All the results were expressed as mean \pm S.E.M. and statistical significance was accepted from $p<0.05$. 


\section{RESULTS}

All the sheep showed estrus behavior and subsequent preovulatory LH surges and ovulation in response to the treatment (Table 1). However, timings of these events were affected by the duration of CIDR insertion and the administration or not of eCG (Figure 1 and Table 1).

In brief, when eCG was not injected, a shorter duration of the CIDR treatment was related with later timings for estrus onset and maximum LH concentration within the preovulatory surge ( $p=0.02$ and $p=0.04$, respectively), a trend for later end of such preovulatory surge $(p=0.06)$ and a later timing of ovulation $(p=0.04)$. However, the intervals estrus-LH surge and LH surge-ovulation were not affected.

Administration of eCG did not induce significant effects excepting an increase in the interval LH peak-ovulation in short-term treatments $(p=0.02)$ and a trend for a shorter interval estrus-LH surge $(p=0.08)$. Hence, although eCG diminishes the differences between short- and long-term treatments and, although occurrence of the different events were still later in the 5-days treatments, these differences only reached significance when considering time of ovulation $(p=0.03)$.

The maximal differences were found when comparing the classical treatment $(\mathrm{G} 14 \mathrm{eCG})$ with the proposed alternative (G5C), since G5C showed a longer interval estrus-LH $(p=0.02)$, a trend for later beginning of the preovulatory LH peak $(p=0.08)$ and significantly later timing of maximum LH concentration $(p=0.03)$ and end of the surge $(p=0.03)$ and a later timing of ovulation $(p=0.04)$.

Conversely, there were no significant differences among groups in the maximum concentration and the AUC of the preovulatory LH surge, in spite of numerically higher values in sheep without eCG, or in the ovulation rate obtained in response to the treatment. 
101

102

103

104

105

106

107

108

109

110

111

112

113

114

115

116

117

118

119

120

121

122

123

124

\section{DISCUSSION}

The present study supports that 5-days short-term CIDR treatments without administration of eCG are equally effective for inducing estrus behavior, preovulatory LH discharge and ovulation in sheep than classical protocols based on 14-days treatments plus eCG at CIDR withdrawal. Previous studies of our group have shown that fertility after natural mating is also similar between these treatments (Martinez-Ros et al., 2019). However, current results indicate that both the short-term CIDR treatment and the absence of eCG caused a delay in the appearance and length of the LH surge and onset of ovulation, in around 16 hours when G14eCG and G5C were compared.

Hence, for optimizing the fertility yields, timing of fixed-time artificial insemination after protocols of 5-days of CIDR treatment without eCG should be adapted for adjusting it to the timing of ovulation.

These results are in agreement with a recent study comparing characteristics of the preovulatory LH surge in response to short- and long-term CIDR treatments (Soriano et al. 2018). However, such study remarks that these differences only occur during the breeding season, which may be related to differences in the endogenous LH secretion between anestrous and reproductive season (Joseph et al. 1992). Therefore, there is a necessity of further studies for evaluating effectiveness and timing of preovulatory events in nonbreeding season, when LH secretion and ovulation are depressed (Joseph et al. 1992).

\section{ACKNOWLEDGMENTS}

The authors thank the CEU-Cardenal Herrera farm staff for their assistance with animal care and handling. 


\section{CONFLICT OF INTEREST}

126 All authors declare no competing interests for publication in this Journal.

127

MU, designing and performing the study and writing the article; TE, designing the study and performing the data analysis and final revision of the article; ARA, collection of animal data and final revision of the article; AGB, designing the study and writing the article; PMR, designing the study and writing the article.

\section{REFERENCES}

135 Abecia, J.A., Forcada, F., \& Gonzalez-Bulnes, A. (2012). Hormonal control of reproduction in small ruminants. Animal Reproduction Science 130, 173-179.

Joseph, I.B.J.K., Currie, W.D. \& Rawlings, N.C. (1992). Effects of time after ovariectomy, season and oestradiol on luteinizing hormone and follicle-stimulating hormone secretion in ovariectomized ewes. Journal of Reproduction and Fertility 94, 511-523.

Martinez-Ros, P., Astiz, S., Garcia-Rosello, E., Rios-Abellan, A., Gonzalez-Bulnes, A. (2018a). Effects of short-term intravaginal progestagens on the onset and features of estrus, preovulatory LH surge and ovulation in sheep. Animal Reproduction Science $197,317-323$.

Martinez-Ros, P., Lozano, M., Hernandez, F., Tirado, A., Rios-Abellan, A., LópezMendoza, M.C., Gonzalez-Bulnes, A. (2018b) Intravaginal device-type and treatmentlength for ovine estrus synchronization modify vaginal mucus and microbiota and affect fertility. Animals, 8, 226. 
148 Martinez-Ros, P., Rios-Abellan, A., Gonzalez-Bulnes, A. (2019). Influence of 149 progesterone-treatment length and eCG administration on appearance of estrus 150 behavior, ovulatory success and fertility in sheep. Animals, 9, 9.

151 Menchaca, A., dos Santos-Neto, P.C., Cuadro, F., Souza-Neves, M., Crispo, M. (2018) 152 From reproductive technologies to genome editing in small ruminants: An embryo's 153 journey. Animal Reproduction 15, 984-995.

154 Soriano, G.A.M., de Ruediger, F.R., Zundt, M., Gomes, M.A.D.C.N., de Souza, L.F.A., 155 Giometti, I.C., de Paula Nogueira, G., Zanelli, G.R., de Almeida Rego, F.C., Castilho, 156 C. (2018). Characterization of the LH peak after short and long fixed-time artificial 157 insemination protocols in sheep raised in the tropics. Animal Science Journal 89, $1245-$ $158 \quad 1252$.

159 Swelum, A.A., Alowaimer, A.N., Abouheif, M.A. (2015). Use of fluorogestone acetate 160 sponges or controlled internal drug release for estrus synchronization in ewes: Effects of 161 hormonal profiles and reproductive performance. Theriogenology 84, 498-503. 
163

164

165

166

Table 1. Percentage, timing of occurrence and characteristics of the preovulatory events in sheep treated with Controlled Internal Drug Release (CIDR) for five and fourteen days (groups G5 and G14, respectively), with or without equine chorionic gonadotrophin

\section{Estrus behavior}

\begin{tabular}{lcccc}
\hline Occurrence (\%) & $100 \%$ & $100 \%$ & $100 \%$ & $100 \%$ \\
\hline Onset (h) & $33.7 \pm 3.0^{1}$ & $34.0 \pm 5.0$ & $39.2 \pm 4.0$ & $44.4 \pm 2.8^{2}$ \\
\hline
\end{tabular}

Preovulatory LH surge

\begin{tabular}{lcccc}
\hline Occurrence (\%) & $100 \%$ & $100 \%$ & $100 \%$ & $100 \%$ \\
\hline Onset (h) & $42.7 \pm 3.8$ & $38.0 \pm 5.2$ & $46.4 \pm 4.8$ & $51.2 \pm 4.3$ \\
\hline $\begin{array}{l}\text { Interval estrus }- \\
\text { LH peak (h) }\end{array}$ & $16.3 \pm 2.1$ & $10.7 \pm 2.0$ & $13.6 \pm 3.8$ & $18.8 \pm 2.1^{\dagger}$ \\
\hline $\begin{array}{l}\text { Timing of } \\
\text { maximum LH } \\
\text { levels (h) }\end{array}$ & $50.0 \pm 4.6^{1}$ & $44.7 \pm 6.0$ & $52.8 \pm 5.1$ & $63.2 \pm 2.7^{2 \dagger}$ \\
\hline End (h) & $61.3 \pm 3.0$ & $56.0 \pm 4.5$ & $61.6 \pm 4.5$ & $70.4 \pm 2.7^{\dagger}$ \\
\hline Duration (h) & $18.7 \pm 2.2$ & $18.0 \pm 2.3$ & $14.4 \pm 1.6$ & $19.2 \pm 2.7$ \\
\hline $\begin{array}{l}\text { Maximum LH } \\
\text { concentrations } \\
\text { (ng/mL) }\end{array}$ & $19.1 \pm 4.3$ & $10.2 \pm 2.3$ & $16.5 \pm 5.3$ & $22.4 \pm 6.7$ \\
\hline AUC (ng x h/mL) & $129.4 \pm 30.0$ & $81.8 \pm 19.7$ & $94.9 \pm 27.5$ & $149.5 \pm 36.7$ \\
\hline Ovulation & & & & \\
\hline
\end{tabular}

\begin{tabular}{lcccc}
\hline Occurrence (\%) & $100 \%$ & $100 \%$ & $100 \%$ & $100 \%$ \\
\hline Onset (h) & $64.7 \pm 3.2^{1}$ & $58.0 \pm 3.7^{1}$ & $72.0 \pm 3.6^{2}$ & $74.8 \pm 2.6^{2 \dagger}$ \\
\hline $\begin{array}{l}\text { Interval LH peak } \\
- \text { ovulation (h) }\end{array}$ & $14.7 \pm 1.4$ & $13.3 \pm 2.7$ & $19.2 \pm 2.4^{\mathrm{a}}$ & $11.6 \pm 0.7^{\mathrm{b}}$ \\
\hline Ovulation rate & $1.7 \pm 0.2$ & $1.7 \pm 0.3$ & $1.8 \pm 0.2$ & $1.4 \pm 0.2$
\end{tabular}

167 Different superscripts indicate significant differences among treatments with different length 168 (numbers; $1 \neq 2: p<0.05$ ), with or without eCG (letters; $a \neq b: p<0.05$ ) and between the 169 classical treatment (G14eCG) and the proposed alternative (G5C) (symbols; $\square \neq \dagger ; p<0.05$ ) 
2

172 characteristics of the preovulatory events in sheep treated with Controlled Internal Drug 173 Release (CIDR) for five and fourteen days (groups G5 and G14, respectively), with or 174 without equine chorionic gonadotrophin (groups eCG and C, respectively). 


\section{LH $(\mathrm{ng} / \mathrm{mL})$}

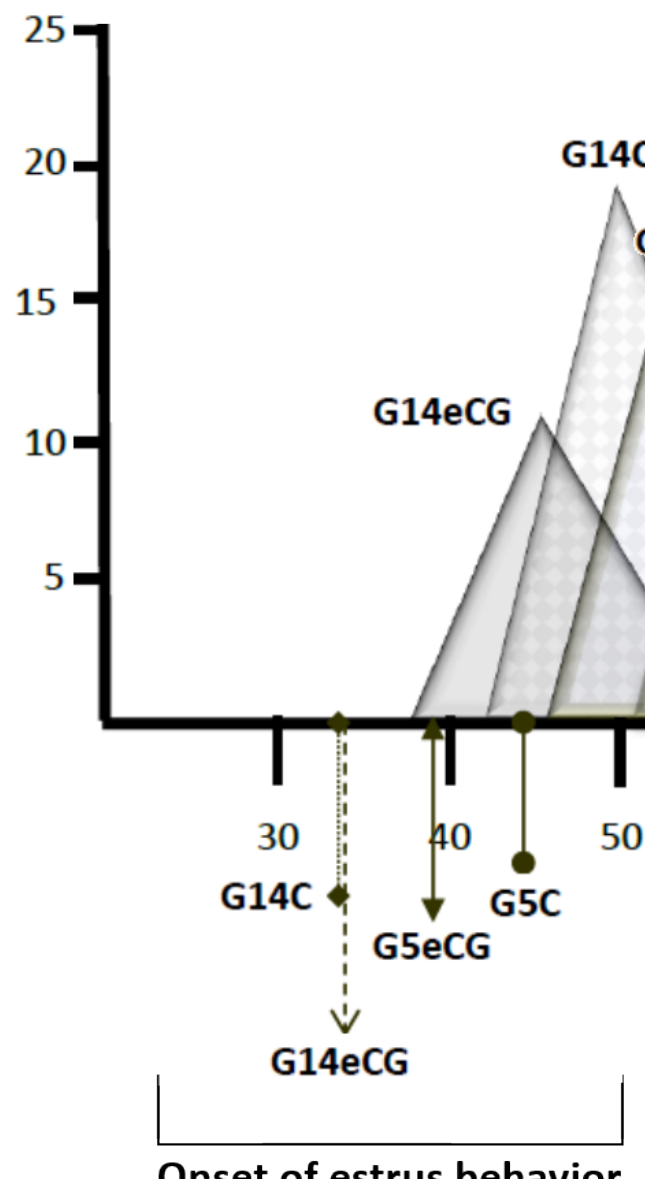

Onset of estrus behavior

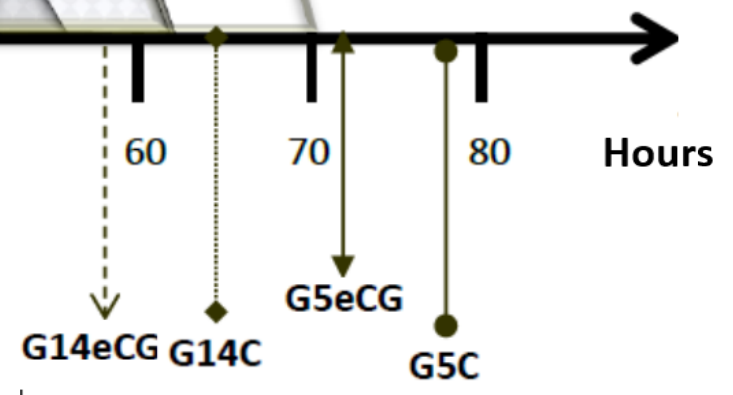

